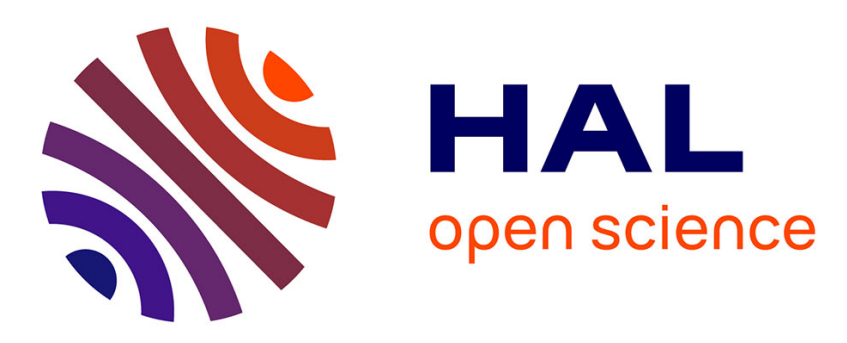

\title{
Validation of image processing tools for 3-D fluorescence microscopy
}

Alain Dieterlen, Chengqi Xu, Marie-Pierre Gramain, Olivier Haeberlé, Bruno

Colicchio, Christophe Cudel, Serge Jacquey, Emanuelle Ginglinger, Georges Jung, Eric Jeandidier

\section{To cite this version:}

Alain Dieterlen, Chengqi Xu, Marie-Pierre Gramain, Olivier Haeberlé, Bruno Colicchio, et al.. Validation of image processing tools for 3-D fluorescence microscopy. Comptes Rendus Biologies, 2002, 325 (1), pp.327-334. 10.1016/S1631-0691(02)01448-8 . hal-00951356

\section{HAL Id: hal-00951356 https://hal.science/hal-00951356}

Submitted on 24 Feb 2014

HAL is a multi-disciplinary open access archive for the deposit and dissemination of scientific research documents, whether they are published or not. The documents may come from teaching and research institutions in France or abroad, or from public or private research centers.
L'archive ouverte pluridisciplinaire HAL, est destinée au dépôt et à la diffusion de documents scientifiques de niveau recherche, publiés ou non, émanant des établissements d'enseignement et de recherche français ou étrangers, des laboratoires publics ou privés. 


\title{
Validation of Image Processing Tools for 3-D Fluorescence Microscopy.
}

\section{Validation d'outils de traitement d'images en microscopie 3D de fluorescence.}

\author{
A. Dieterlen ${ }^{1}$, C. Xu ${ }^{1}$, M-P. Gramain ${ }^{2}$, O. Haeberlé ${ }^{1}$, B. Colicchio ${ }^{1}$, \\ C. Cudel ${ }^{1}$ and S. Jacquey ${ }^{1}$ \\ ${ }^{1}$ Groupe Lab.El, Laboratoire MIPS, EA 2332, Université de Haute-Alsace \\ IUT de Mulhouse, 61 rue Albert Camus 68093 Mulhouse Cedex \\ 2I.M.A.C., CRAN, UPRES-A 7039 \\ Centre Alexis Vautrin, 54500 Vandœuvre-Les-Nancy \\ E. Ginglinger ${ }^{3}$, G. Jung ${ }^{4}$, E. Jeandidier ${ }^{3}$ \\ ${ }^{3}$ Laboratoire de Génétique \\ ${ }^{4}$ Laboratoire d'Hématologie \\ Centre Hospitalier de Mulhouse, 68070 Mulhouse Cedex
}

Proofs should be send to :

Alain Dieterlen

Groupe Lab.EI, Laboratoire MIPS

IUT, 61, rue Albert Camus 68093 Mulhouse Cédex France

Tél.: 0389337661 Fax : 0389337605

Email: a.dieterlen@univ-mulhouse.fr 


\section{Abstract.}

3-D optical fluorescent microscopy becomes nowadays an efficient tool for volumic investigation of living biological samples. Using optical sectioning technique, a stack of 2-D images is obtained. However, due to the nature of the system optical transfer function and non-optimal experimental conditions, acquired raw data usually suffer from some distortions. In order to carry out biological analysis, raw data have to be restored by deconvolution. The system identification by the point spread function is useful to obtain the knowledge of the actual system and experimental parameters, which is necessary to restore raw data. It is furthermore helpful to precise the experimental protocol.

In order to facilitate the use of image processing techniques, a multi-platform compatible software package called VIEW3D has been developed. It integrates a set of tools for the analysis of fluorescence images from 3-D widefield or confocal microscopy. A number of regularization parameters for data restoration are determined automatically. Common geometrical measurements and morphological descriptors of fluorescent sites are also implemented to facilitate the characterization of biological samples. An example of this method concerning cytogenetics is presented.

Keywords : Identification, 3-D Deconvolution, 3-D quantification, Fluorescence microscopy, FISH (Fluorescent In Situ Hybridization).

\section{Résumé.}

La microscopie 3D de fluorescence est un moyen efficace d'investigation volumique de spécimens biologiques. L'acquisition d'images tridimensionnelles repose sur le déplacement relatif de l'objet par rapport à l'objectif effectuant ainsi un "découpage optique". Les déformations dues aux singularités de la fonction de transfert optique rendent indispensable une restauration des images avant toute mesure quantitative 3D. L'identification de la réponse impulsionnelle permet de préciser les protocoles d'acquisition. La connaissance du modèle de formation d'image est nécessaire à l'optimisation de la déconvolution. Différents algorithmes de déconvolution ont été implémentés, le choix des paramètres de régularisation a été automatisé.

Dans le but de faciliter l'utilisation de ces outils d'investigation aux utilisateurs, un logiciel VIEW3D a été réalisé, intégrant la visualisation des images 3D, l'identification de la fonction de transfert, la déconvolution et l'analyse des résultats. Cette boite à outils développée sous environnement PV-WAVETM est évolutive et multi-plate-forme.

L'enjeu de ce travail est de proposer des conditions analytiques reproductibles validées sur des échantillons d'intérêt clinique. Un exemple d'application en cytogénétique est présenté.

Mot clefs: Identification, Déconvolution 3D, Quantification 3D, Microscopie de fluorescence, FISH (Fluorescent In Situ Hybridization). 


\section{Abridged version}

La microscopie photonique trouve un nouvel essor avec l'avènement de nouvelles technologies et passe d'observations classiques en deux dimensions à des acquisitions d'images tridimensionnelles d'échantillons biologiques vivants fluorescents.

L'acquisition d'images tridimensionnelles d'objets transparents repose sur l'utilisation d'un dispositif spécifique qui permet d'effectuer un "découpage optique" (optical sectioning microscopy) de l'objet par déplacement axial de l'objectif. Les caractéristiques particulières (perte de fréquences spatiales ou "missing cone", singularité à l'origine) de la fonction de transfert optique (Optical Transfer Function ou OTF) rendent indispensable la restauration (ou déconvolution) des images avant toute mesure quantitative 3D.

La réponse impulsionnelle optique appelée PSF (pour Point Spread Function) caractérise le système d'acquisition. Elle peut être mesurée ou calculée à partir de modèles scalaires ou vectoriels. Utilisant le model scalaire de Gibson et Lanni associé à des données expérimentales, un outil statistique permettant l'identification de la réponse impulsionnelle a été développé. L'analyse théorique et expérimentale de l'influence des paramètres d'acquisition est essentielle pour optimiser le protocole d'acquisition sur échantillons biologiques.

La restauration devra améliorer la qualité des données : corriger les distorsions géométriques et réassigner les intensités à leurs origines. Une restauration de qualité nécessite la connaissance du système d'acquisition et donc de son OTF. Des informations a priori sur le spécimen étudié peuvent aussi s'avérer utiles. Quatre algorithmes de déconvolution ont été implémentés, réalisant soit une inversion directe régularisée (LLS et MAP) soit une inversion itérative (ML-EM et l'algorithme de Carrington). Pour mener à bien la restauration, les paramètres de régularisation sont déterminés par une procédure automatique minimisant une 
fonction de coût adaptée. Cette automatisation doit permettre une plus grande facilité d'utilisation et une meilleure répétitivité inter-utilisateur.

Si l'on décompose en quatre parties le processus d'analyse d'images en microscopie de fluorescence, on distinguera : l'acquisition des données, la déconvolution, la quantification et enfin l'interprétation des données. Les outils d'investigation ont été intégrés dans un logiciel appelé VIEW3D, dans le but de faciliter leur utilisation. Dans cet environnement sont regroupés les outils de visualisation $3 \mathrm{D}$, d'identification de la fonction de transfert, quatre algorithmes de déconvolution automatisés et des outils de mesure 3D.

A l'aide de billes fluorescentes de référence, ces outils sont testés en particulier pour déterminer le facteur d'élongation axiale afin d'effectuer la correction. Les analyses statistiques, géométriques ou morphologiques deviennent alors significatives.

Pour illustrer ces travaux, cette méthodologie est appliquée sur des images de noyaux cellulaires marqués par une molécule fluorescente constituée d'une sonde d'ADN marquée à la rhodamine utilisée en cytogénétique.

Les premiers résultats obtenus sont prometteurs. Cependant, les études sur échantillons biologiques sont assez complexes en raison de la diversité de la distribution de l'intensité et de la morphologie des zones d'analyse. Ceci implique de rendre le processus de déconvolution adaptatif par l'utilisation de pré-traitements des zones d'intérêt biologique. 


\section{Introduction}

Three-dimensional intracellular structure data are often necessary in biological study. Thus, it may be helpful to detect cell events if one can localize fluorescent probes targeted to cell compounds such as cell proteins or DNA sequences. These measurements may be obtained by multi-labeling techniques involving multi-wavelength acquisition [1]. The numbering of chromosome copies within interphase cells using alpha-satellite or locus specific fluorescent probes is a powerful approach to detect chromosomal number abnormalities [2] but requires accurate optical conditions in order to localize and separate fluorescent sites within nuclei [3].

The 3-D data can be acquired by Optical Sectioning Microscopy (OSM) which is performed by axial stepping of the object versus the objective. A stack of 2-D images is the optical equivalent of a series of microtome slices, allowing a 3-D reconstruction of a specimen. Most of the three-dimensional fluorescence microscopy techniques now use a confocal microscope [4]. Compared to the conventional fluorescence microscope, the confocal microscope design reduces haze from out of focal-plane objects. Although confocal microscopy has many advantages, it does have some limitations. The amount of excitation light required to produce a confocal image may be a problem for fixed specimens labeled with several different dyes and for long-term 3-D imaging of living samples.

The image formed by a conventional fluorescence microscope contains light from throughout the specimen. What is actually present in the focal plane may be blurred by this "out-offocus" fluorescence. Reduction of this side effect is the aim of 3-D microscopy [5]. Particularly in conventional microscopy, this reduction is carried out computationally by deconvolution process.

The characterization of the out-of-focus light is based on the 3-D image of a point-like source, the so-called Point Spread Function (PSF). The image formation process can be described by the following convolution equation: 


$$
g(X)=\int_{-\infty}^{+\infty} h\left(X-X_{1}\right) f\left(X_{1}\right) d X_{1}+b(X)
$$

where $\mathrm{X}$ and $\mathrm{X}_{1}$ are 3-D coordinates, $\mathrm{g}(\mathrm{X})$ is the recorded image, $\mathrm{h}(\mathrm{X})$ the PSF of the system and $f(X)$ the original object. The term $b(X)$ represents a random process which is a combination of additive noise sources due to the photon emission process and the data acquisition system. Specificities of the image formation process in an optical microscope introduce aberrations and intensity distributions, such as axial elongation and intensity artifacts $[6,7]$. Due to these distortions, original images from the microscope cannot be used directly for quantitative measurements like size and intensity, but need restorations before any analysis.

Image processing is a key element, and a lot of efforts have been devoted to develop specialized computer tools. To summarize, one can split this process in four steps: image acquisition, deconvolution, feature extraction which give various data: number, size and intensity distributions of fluorescent sites for example, and eventually at the end the biological interpretation of processed data. The data acquisition requires full hardware control of the acquisition system (filter selection, stage scanning, illumination and image acquisition synchronization). As a consequence, specialized softwares are provided by manufacturers $\left(\mathrm{EPR}^{\mathrm{TM}}\right.$, DeltaVision $\left.{ }^{\mathrm{TM}}\right)$ of the processing system.

A tremendous work has been dedicated to fluorescence image deconvolution in recent years. This has led to the development of special image processing softwares (XCOSM, BitPlane $\left.^{\mathrm{TM}} \ldots\right)$. The data analysis is often performed using more general tools like Noesys ${ }^{\mathrm{TM}}$ or Analyze $^{\mathrm{TM}}$. So, to analyze a single specimen the biologists often have to use several platforms and/or softwares.

In the mind of simplifying the 3-D fluorescent images exploitation, a package integrating all the tools necessary for a complete biological analysis, called VIEW3D, has been developed. It 
is a package allowing in a simple environment modelization and identification of microscopy systems, and the deconvolution, and the visualization and measurements of data. Since this processing takes into account the experimental conditions, the results obtained using this method is supposed to be more reproducible, improving the reliability in medical analysis. An example of application in the fields of cytogenetics is provided in Part 4.

\section{Methods}

\subsection{System identification}

In order to characterize the optical system, it is necessary to measure the PSF which describes the properties of the image acquisition system. The three-dimensional Fourier transform of the PSF is called the Optical Transfer Function (OTF) of the system. The OTF describe the spatial frequency distribution. The PSF is function of different instrumental parameters such as the numerical aperture (N.A.), the emission wavelength $\left(\lambda_{e m}\right)$, the refractive indices of the different media along the optical path and optical aberration of the lens [8]. Consequently, it is useful to quantify the variations in the PSF distribution induced by different conditions of observation. A PSF can be either measured or computed. Experimental PSFs are obtained by imaging small fluorescent latex beads (Interchim or Molecular Probes). Ideally the microspheres should be as small as possible, but the smallest ones are weak in intensity and bleach rapidly. A trade-off must be found to define the microsphere diameter according to the characteristics of the microscope objective in use. Usually beads with a diameter of about one third of the Rayleigh criterion are used [9]. Computed PSFs are noiseless, however they do rely on a simplified model of the microscope. Furthermore, the assumed experimental parameters in the computational model may differ from their actual values. Statistical tools have been developed to quantify the variation of the PSF as function of the optical parameters: fluorescence wavelength, N.A. of the objective, refractive index of the immersion oil, optical tube length and specimen thickness. They are based on higher order statistical 
moments, known as excellent descriptor of energy distribution and symmetries of the PSFs as well as the aberrations of the system [10].

The study of system identification has been first carried out on PSFs computed with the Gibson and Lanni model [11], then applied to experimental PSFs. Even if a good correlation is observed between simulations and experiments, experiments are the only methods allowing to characterize optical aberrations like chromaticity and asymmetry of the system.

A specific adapted protocol may be proposed by determining the precise influence of the different experimental parameters on PSF.

\subsection{Deconvolution}

The main objective of deconvolution is to reduce the image distortions by redistributing the fluorescence intensities and reconstructing geometrical shape of the sample. Numerous deconvolution methods have been described in the literature $[12,13]$. Up to now, we have focused our attention on methods using the PSF and technique being well adapted to fluorescence microscopy: such as non-iterative LLS (Linear Least square Solution developed by Preza [14,15]) and Maximum A Posteriori (MAP) [16] algorithms, iterative ML-EM (Maximum-Likelihood Expectation Maximization developed by Holmes [17]) and the Carrington [18] algorithms. The reader may refer to published literature for a detailed description of these algorithms. These methods do take into account the system singularity and the presence of noise. However a number of regularization parameters should be introduced by users, which may modify the subjectivity of the results. In order to determine this parameter automatically, the sum of the image bias error and the noise variance is minimized (using VIEW3D), according to the PSF of the image acquisition system. In this way the reproducibility of measurements is improved. 


\section{Materiel}

\subsection{Microscope}

An upright epifluorescence microscope BX-51 PROVIS (Olympus) with a $100 \mathrm{~W}$ xenon lamp as excitation source is used. Image acquisitions are carried out with an apochromatic, infinity corrected, 100X oil immersion objective lens (numerical aperture of 1.4).

The microscope is equipped with the EPR ${ }^{\mathrm{TM}}$ optical sectioning acquisition system: a piezoelectric translation device is inserted in between the motorized revolving nosepiece and the objective. The minimum scanning step is $0.25 \mu \mathrm{m}$ and the maximum scanning range is $100 \mu \mathrm{m}$.

The image sensor used is a Peltier cooled charge coupled device CCD-1317K camera from Princeton Corporation. The pixel size is $6.8 \times 6.8 \mu \mathrm{m}^{2}$ and the matrix dimension is 1317 by 1035 pixels. The intensity is 12 bits coded.

\subsection{Software}

Combining our 3-D fluorescence microscopy with some biologist expertise, a set of tools for the analysis of images from widefield or confocal microscopy has been developed. This all-in one toolbox VIEW3D is developed with PV-WAVE ${ }^{\mathrm{TM}}$ (Unix and Windows compatible). The graphical user interface provides direct access to various operations: image loading and visualization, deconvolution, segmentation, 3-D geometrical measurements and morphological description. The results may be collected and saved under various formats to export them to other softwares (spreadsheets or presentation tools).

VIEW3D graphical interface includes several modules (Figure 1):

- Data acquisition (Figure 2)

- $\mathrm{XY}$ and $\mathrm{XZ}$ plane by plane interactive viewing (Figure 3)

-3-D visualization (Figure 4)

- Confocal or conventional microscope PSF computation

- Deconvolution, segmentation, connected components labeling (Figure 5 and 6)

- Data analysis: shape descriptor, volume and intensity measurements (Figure 7) 
The following deconvolution algorithms are available : LLS, MAP, ML-EM and Carrington's methods. Segmentation is performed by intensity thresholding or via mathematical morphology. The 3-D labelling is provided for analysis and measurements of fluorescence sites. Volumes, surfaces, compactness factors and up to $4^{\text {th }}$ order centered moments (mean, variance, skewness and kurtosis) are implemented. These informations allow quantitative measurements (volumic and intensity distributions) of the fluorescence sites, thus facilitating specimen classification.

\subsection{Biological samples}

Human uncultured amniocytes have been obtained by amniocentesis and spread on microscope slides after centrifugation of $3 \mathrm{ml}$ of amniotic fluid at 1,000 rpm for 8-10 minutes. Fluorescent in situ hybridization (FISH) probes were commercial products available from Vysis (Downers Grove, IL, USA) and applied according to the manufacturer's instructions. Rhodamine labeled locus specific probes (LSP) D21S259, D21S341 and D21S342, spanning the region $21 \mathrm{q} 22.13-\mathrm{q} 22.2$ have been assayed in order to numerate the chromosome 21 copies on interphasic nucleus.

\section{Results}

To validate our program, VIEW3D was firstly experimented using images of calibrated fluorescent beads.

Identification tools allow to characterize aberrations in order to determine if the system is under the design conditions. Some parameters, such as the refractive oil immersion index, the specimen depth and the NA, are the most interesting parameters in order to get an optimal acquisition [19].

Deconvolution methods have been compared regarding to intensity reassignment, geometrical reconstruction and speed. As previously published [20], the $\mathrm{Z}$ elongation and dissymmetries are the main distortions due to both index mismatch and specimen thickness. The 4 methods, implemented in VIEW3D, improve image contrast and reduce the axial elongation. However, ML-EM is more appropriate for volume reconstruction, Carrington's method for intensity 
reassignment of thin specimens and, because of their rapidity, LLS and MAP are more adapted to routine processing [21].

The practical application using some biological samples is currently under evaluation and preliminary results already show a significant improvement in the signal analysis after FISH, using LSP labeling of the 21q22.13-q22.2 chromosomal region. Figure 8 shows the wide intensity spread of the fluorescent spots without image processing. Figure 9 shows the same nucleus area after MAP deconvolution.

\section{Discussion}

Image restoration in 3-D fluorescence microscopy is mandatory to remove artifacts of raw data. Thus, allowing a reliable and reproducible biological analysis.

The precise determination of experimental parameters during the data acquisition is critical to the restoration process. However, many experimental parameters are both specimen dependent, (refractive indices, thickness) and optical condition-dependent (oil refractive indices, NA). The Gibson and Lanni model used in VIEW3D is an user friendly as well as efficient tool since most of the experimental parameters are clearly defined. It may be not adapted to high NA objectives, because of its scalar model of diffraction underpinning. Therefore vectorial theories of diffraction should be more appropriate [22,23].

Preliminary results obtained with FISH on uncultured amniotic fluid cells show a significant improvement in both fluorescent signals localization and separation as presented in Figures 8 and 9. This claims for the efficiency of the method to reduce the wideness of the fluorescence intensity spread, mainly due to the poor resolution along the microscope optical axis $(Z)$, which usually induces artifacts in spots numbering [3].

For some biological specimens, intensity distribution and morphology may vary significantly from one sample to another. The photon noise is signal dependent. It implies that the 
deconvolution process should be adaptive, i.e. regularization parameters even the deconvolution algorithm have to be data driven.

Data volume characterization has been carried out. The purpose of this pre-processing is to split the entire volume into regions characterized by homogeneous statistical and morphological properties. This allows to apply separately appropriate restoration techniques to each of them.

Furthermore, it is mandatory for users to be aware of the shorts of artifacts that can arise and what must be done to reduce them.

\section{Conclusion}

An embedded 3D image processing tool the VIEW3D has been developed to analyze fluorescent images of 3-D biological specimen. It enables the possibility to perform all quantification steps within the same environment. It integrates most of functions required in 3-D biological measurements, i.e., 3-D specimen representation, system identification to define experiment protocol, raw data restoration for artifacts correction, segmentation, geometrical and morphological measurements of fluorescent sites (necessary for specimen analysis).

According to the nature of the studied specimen, this multi-platform compatible software allows users to choose one of the four types of implemented deconvolutions. VIEW3D has been designed in a modular way making it easy to further incorporate new modules.

Both experiments on calibrated reference beads and on biological samples are very encouraging. There is no best deconvolution method. As a general rule, methods that require more computer time yield better results. However, in some cases speed may be critical. A panel of different algorithms being "at hand" in the same package allows to choose first a rapid deconvolution method in order to select interesting samples on which time consuming algorithms will be run.

This experimental approach leads to improved reproducibility of geometrical measurements on biological samples. 


\section{Acknowledgement}

This work has been partially financially supported by an CNRS PCV98/082 project (100KFr), in collaboration with the Department of membrane protein and receptors (CNRS UPR 9050) directed by Dr. Jean-Luc Galzi.

We also thank the biologists from the research laboratory in oncology of the "Centre Alexis Vautrin" (Vandoeuvre-les-Nancy, France) directed by Pr. Jean-Louis Merlin, especially Corinne Bourg-Dill for her contribution on biological applications.

The authors are grateful to Dr. D. Dumas (Laboratoire d'AngioHématologie-Hémorhéologie, Faculté de Médecine, Vandoeuvre-les-Nancy, France) for his contribution to 3-D microscopy acquisitions.

\section{References}

[1] Bour-Dill C., Gramain M.P., Merlin J-L., Marchal S., Guillemin F., Determination of intracellular Organelles Implicated in Daunorubicin Cytoplasmic Sequestration in MultidrugResistant MCF-7 Cells Using Fluorescence Image Analysis, Cytometry, 39, (2000), 16-25.

[2] Philip J., Bryndorf T., Christensen B., Prenatal aneuploidy detection in interphase cells by fluorescence in situ Hybridization (FISH), Prenat Diagn, 14, (1994), 1203-1215.

[3] Bradl J., Hausmann M., Ehemann V., Komitowski D., Cremer C., A tilting device for three-dimensional microscopy: application to in situ imaging of interphase cell nuclei, J. Microsc, 168, (1992), 47-57.

[4] Pawley J.B., Handbook of Biological Confocal Microscopy, Plenum, New York, 1995.

[5] McNally J.G., Karpova T., Cooper J., Conchello J.A., Three-Dimensional Imaging by Deconvolution Microscopy, Methods, 19, (1999), 373-385.

[6] McNally J.G., Preza C., Conchello J.A. and Thomas L.J., Artifacts in computational optical-sectioning microscopy, J. Opt. Soc. Am. A, Vol. 11, N 3, (1994), 1056-1067.

[7] Dieterlen A., Xu C., Chomik A., Meyer J.J., Jung G. and Jacquey S., Artifacts due to shift variant and quasi-monochromatic image formation in 3D reconstruction by sectioning microscopy, Analytical Cellular Pathology, 13, (1997).

[8] Gibson S.F. and Lanni F., Experimental test of an analytical model of aberration in an oilimmersion objective lens used in three-dimensional light microscopy, J. Opt. Soc. Am. A, Vol. 8, No 10, (1991), 1601-1613.

[9] Preza C., Ollinger J.M., McNally J.G., Thomas L.J., Micron. Micros. Acta, 23, (1992), 501-513.

[10] Castaneda R., Two-dimensional evaluation of point spread functions using centered reduced moments, Pure Applied Optics, 3, (1994), 737-755.

[11] Gibson S.F., Modeling the three-dimensional imaging properties of the fluorescence light microscope, Carnegie Mellon University, 1990.

[12] Hunt B. R., Prospects for imaging restoration, International Journal of Modern Physics C, 5, (1994), 151-178. 
[13] Meinel E. S., Origins of linear and nonlinear recursive restoration algorithms, J. Opt. Soc. Am., Vol. 3, $\mathrm{N}^{\circ}$ 6, (1986), 787.

[14] Preza C., Miller M.I., Thomas (L.J.), McNally (Jr.) and McNally (J.G.), Regularized linear method for reconstruction of three-dimensional microscopic objects from optical sections.” J. Opt. Soc. Am. A, 9, (1992), 219-228.

[15] Preza C., Miller M.I. and Conchello J.-A., Image reconstruction for 3-D light microscopy with a regularized linear method incorporating smoothness prior. Proc. SPIE 1905, (1993), 129.

[16] XCOSM, Progiciel, Biomedical Computer Laboratory, Washinton University, St. Louis. [17] Holmes T.J., Maximum likelihood image restoration adapted for noncoherent optical imaging, J. Opt. Soc. Am. A, 5, (1988), 666-673.

[18] Carrington W.A., Image restoration in 3D microscope with limited data, Bioimaging and Two-dimentional spectroscopy SPIE, 1205, (1990), 72-83.

[19] Gramain M.P., Caractérisation tridimensionnelle d'un microscope à épifluorescence, Thèse, Nancy, 2000.

[20] Gramain M.P., Dieterlen A., Xu C., Bour-Dill C., Dumas D., Jacquey S., Guillemin F., Conventional 3-D fluorescence microscopy : Experimental elongation determination, OWLS Series volume VI in press.

[21] Chomik A., Dieterlen A.,Xu C., ., Haeberlé O., Meyer J.J., Jacquey S., Quantification in optical sectionning microscopy: A comparison of some deconvolution algorithms in view of 3-D image segmentation, Journal of Optics, 28, (1997), 1-9.

[22] Török P., Focusing of Electromagnetic Waves Through Dielectric Interfaces: Theory and Correction of Aberration, Optical Memory and Neural Networks, 8, 1999, 1.

[23] Egner A., Hell S.W., Equivalence of the Huygens-Fresnel and Debye approach for the calculation of high aperture point-spread functions in the presence of refractive index mismatch., J. Microsc., 193, (1999), 244-249. 


\section{Figure legends}

Fig. $\mathrm{n}^{\circ} 1$ : "VIEW3D" main menu, the left buttons are dedicated to visualization and right ones to images processing tools. The icon images represent the central plane of loaded data.

Fig. $\mathrm{n}^{\circ}$ 2: View box for raw data acquisition, the user is invited to precise header size, data format and volume size.

Fig. $n^{\circ}$ 3: Section visualisation of a cell nucleus. The $17^{\text {th }} X Y$ plane is presented above and the $27^{\text {th }} \mathrm{XZ}$ section below.

Fig. $\mathrm{n}^{\circ}$ 4: 3 -D visualisation of a cell nucleus. The embedding box is indexed by the $\mathrm{X}, \mathrm{Y}$ and $\mathrm{Z}$ coordinates.

Figure $n^{\circ}$ : Section visualisation of a cell nucleus after MAP deconvolution. the $17^{\text {th }} X Y$ plane is presented above and the $27^{\text {th }} \mathrm{XZ}$ section below.

Figure $n^{\circ} 6$ : Section visualisation of the deconvolved cell nucleus after segmentation. The $17^{\text {th }}$ $\mathrm{XY}$ plane is presented above and the $27^{\text {th }} \mathrm{XZ}$ section below.

Figure $n^{\circ} 7$ : Results in the box of measurements obtained after processing are presented. 5 different fluorescent sites are detected, surfaces and volumes are calculated.

Figure $\mathrm{n}^{\circ}$ 8: Sections of amniotic cell nucleus labeled with rhodamine labeled DNA probe targeted to the 21q22.13-q22.2 chromosome region before deconvolution.

Figure $\mathrm{n}^{\circ} 9$ : Same sections of amniotic cell nucleus labeled with rhodamine labeled DNA probe targeted to the 21q22.13-q22.2 chromosome region after MAP deconvolution. 
Figures

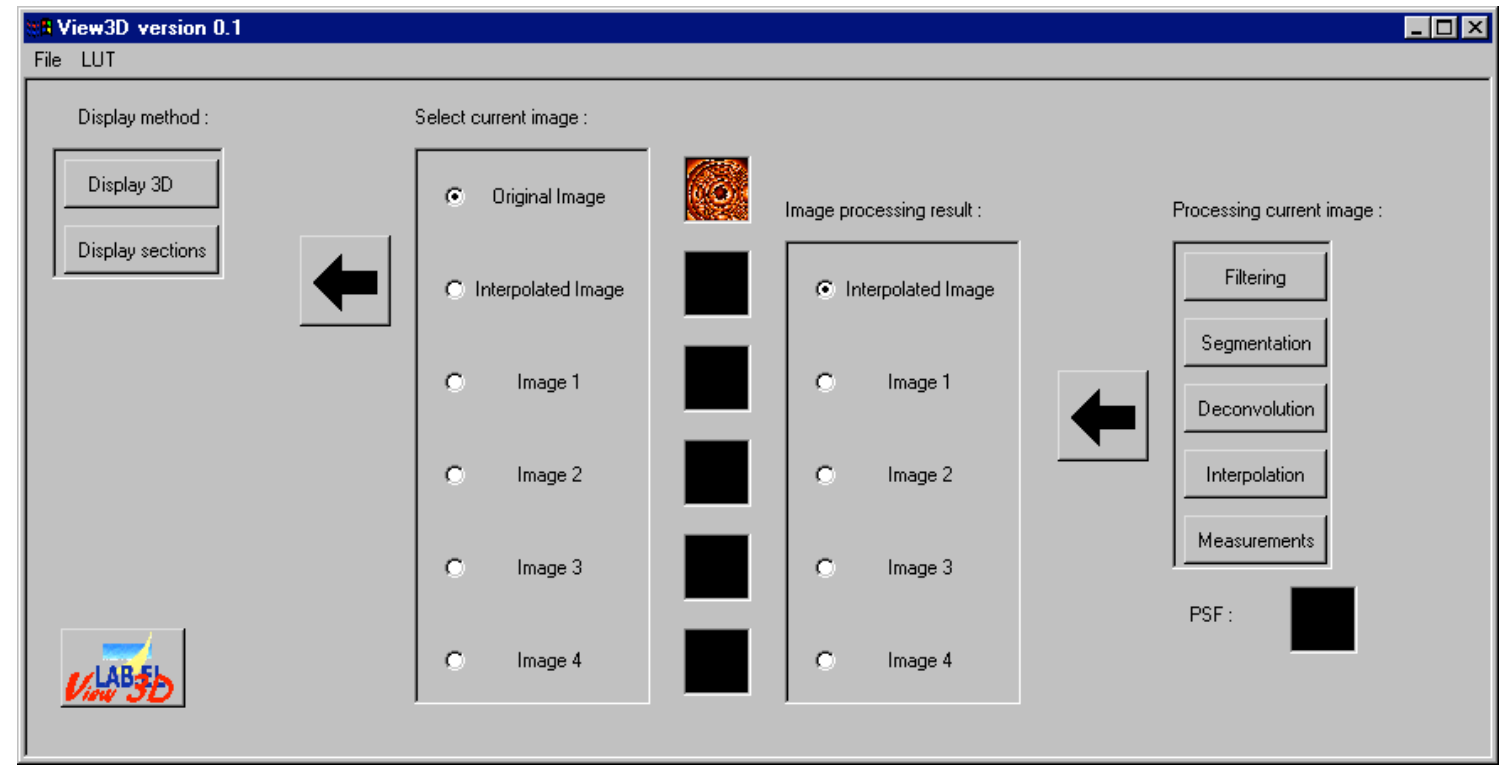

Fig 1 


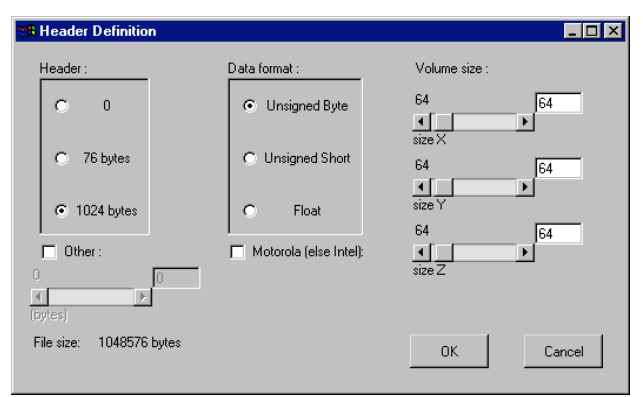

Fig 2

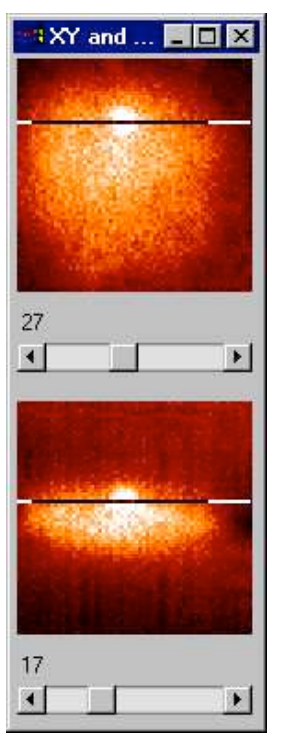

Fig3

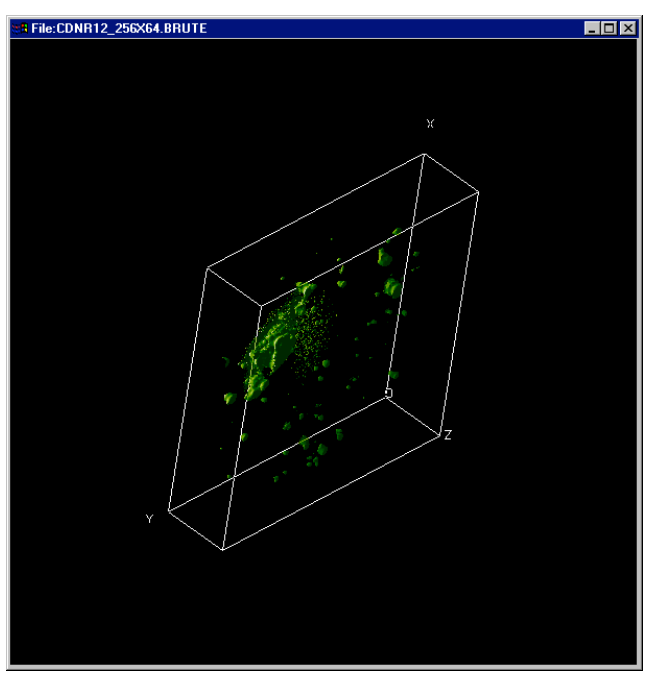

Fig4 


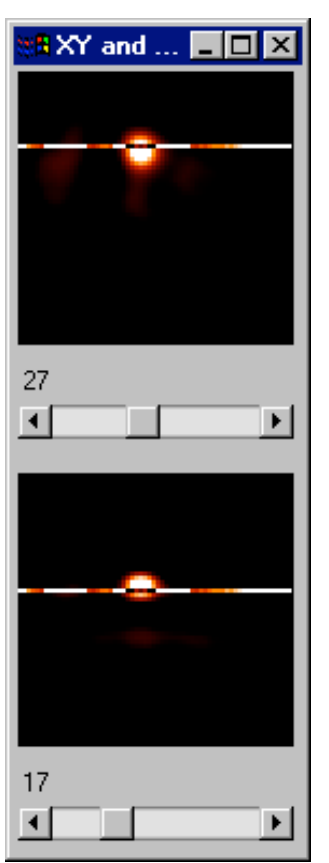

Fig 5

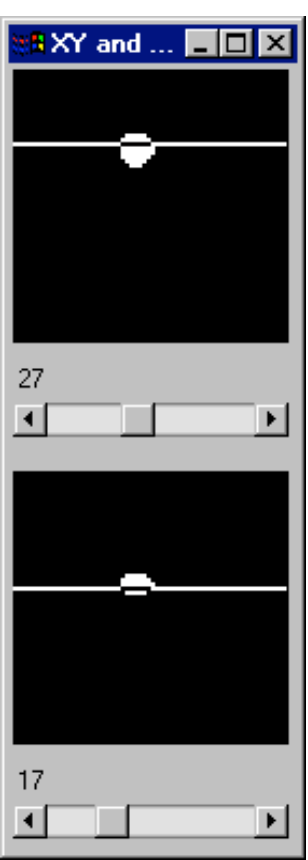

Fig 6 


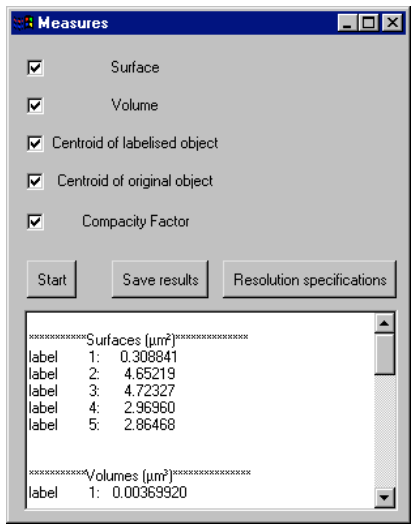

Fig 7

$\rightarrow X Y$ and $X Z$ sections
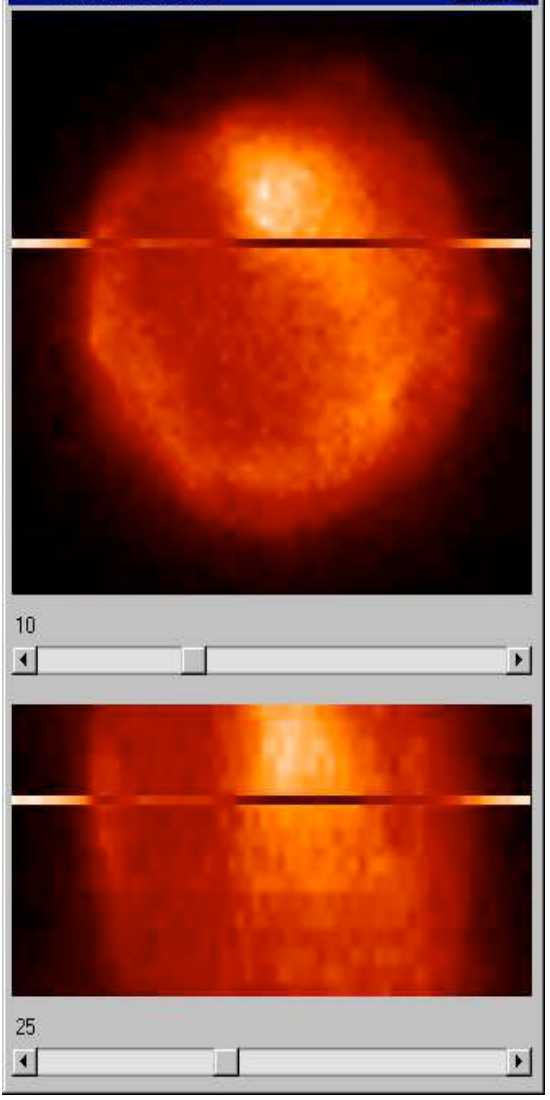

Fig 8 


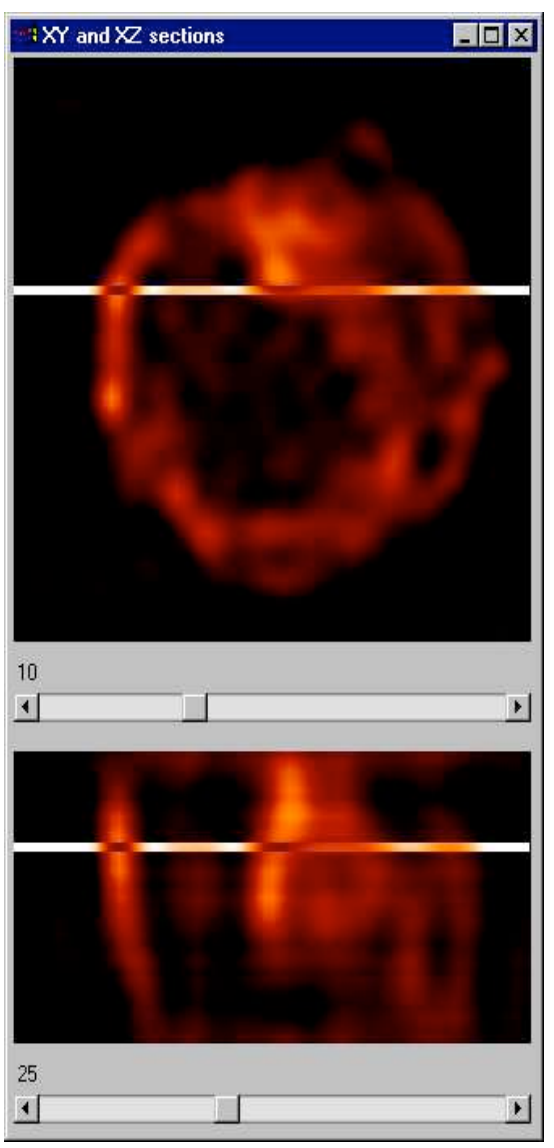

Fig 9 